\title{
Adolescente e drogas
}

Ruy de Mathis*

O uso de drogas não é um fato novo na história da humanidade. Há registro de uso de substâncias tóxicas a mais ou menos 4000 anos antes de Cristo. Este uso era normalmente associado a funções religiosas por seus líderes comunitários. $\mathrm{Na}$ antiga China seu uso era espalhado pela população em geral.

Hoje temos vários fatores desencadeantes onde os jovens, e principalmente estes fazem uso de elementos estranhos a necessidade orgânica e social para poderem ficar alienados, isolados ou hiper-ativos do mundo que vivemos.

\section{CONCEITOS}

O abuso de drogas é também conhecido na literatura por dependência física, psíquica, emocional, hábito, vício, toxicomania e mais adição de drogas e farmaco dependentes. Preferimos o termo abuso, porque além da 
dependência as drogas também causam fenômenos de abstinência e mantém o adolescente em constante estado de preocupação.

Dependência é a urgência de tomar a droga; os fenômenos de abstinência se caracterizam por dores, palpitações na ausência da droga; no ponto de vista psicológico o fato mais importante é a preocupação com a droga.

No púbere a no adolescente, é o estado de preocupação que causa a ruptura com o meio ambiente, impedindo sua adaptação na família, na escola no trabalho, e nos relacionamentos heterossexuais; o jovem passa a buscar somente as fontes que correspondam as sua necessidades determinadas pela preocupação pela droga.

Com o abuso ocorre, além da marginalização social, a facilitação para crimes contra propriedade e contra as pessoas, perda de conceitos éticos ou morais e continua deterioração da personalidade.

Vamos encontrar na literatura alguns sinônimos para o termo dependência tais como:

Usuário, dependente, drogado, drogadito, adicto, toxicômano, droga dependente e viciado entre outros; os especialistas usam as expressões acima para desicgnar o jovem.

O drogadito é sempre dominado por angústia e temores cuja a realidade os transformam em sentimentos insuportáveis para seu ego. A insegurança em si próprio e o medo de ser destruido demonstram pela constância com que se evidenciam e a intensidade com que se apossam deste tipo de personalidade, que a estrutura do (eu) do toxicômano potencial é notavelmente fraca.

\section{CAUSA DO ABUSO}

São múltiplas as teorias sobre o abuso; podemos quase dizer que se igualam em números aos trabalhados publicados. Cada autor tem uma teoria: a conclusão é pois que é suficientemente válida, ou todas têm falhas. $\mathrm{O}$ que está notório é que a escalada do abuso de drogas é crescente e os tratamentos têm sucesso muito reduzido.

Freqüentemente em reuniões de especialista uns não entendem os outros em terminologia e teorias. Existem as mais variadas abordagens: as drogas passam a ser estudadas pela especialidade químicas e farmacológicas, psiquiátricas, sociológicas e morais, legais e penais. Poderíamos dizer que a adição é um sintoma de alguma deficiência ou carência químico-psicológico-ético-social no indivíduo ou na sociedade. 
A preocupação mascara o que esta subjacendo no indivíduo e o que ele não é capaz de enfrentar. A preocupação faz o indivíduo buscar a droga e não o que ele realmente precisa, seja prazer, compensação para frustrações afetivas, revoltas com o status social, inseguranças sexuais, excesso de lazer e sintomas psicológicos e psiquiátricos.

A preocupação com a droga faz o indivíduo se alienar do que acontece entre sua pessoa e o meio. A preocupação cria o abismo entre o eu e o mundo.

O novo impulso, o de dependência, se desenvolve à semelhança dos outros impulsos, que uma vez despertados precisam encontrar sua satisfação. É um impulso artificial que tem as mesma manisfestações dos instintos ou impulsos naturais.

O importante para nós é descobrir precocemente o que a preocupação esta mascarando, se é problema social, religioso, ou se é de substrato bioquímico.

\section{DEPENDÊNCIA PSÍQUICA E PSICOLOGIA}

É uma situação onde há uma satisfação e uma atitude que requerem uma periódica e continua administração de droga para produzir prazer ou evitar desconforto. Esse estado mental segundo a OMS é o mais poderoso de todos os fatores envolvidos na intoxicação crônica. Com certos tipos de drogas, ele pode ser o único fator envolvido. Já a dependência fisica é um estado adaptativo que se manifesta por distúrbios físicos quando se suspende a droga; esta dependência é um poderoso fator no reforço da influência da dependência psíquica do uso continuo de uma droga.

Quail são as circunstancias que levam ao uso das drogas de forma tão insensata? Há pessoas que acredita que tomando essas drogas estão aumentando sua capacidade intelectual, ou que com isso adquirem coragem "Psicológica" para enfrentar dificuldades sociais ou profissionais ou ainda serem sexualmente mais capazes.

Há no entanto vários fatores bio-psico-sociais, farmacológico, e ambientais no uso da droga.

KRAMER e CAMERON, acreditam que a explicação dessa pratica envolve:

1. Manifestação de desordem de caráter.

2. Manifestação de desvio comportamental delinqüente. 
3. Tentativa de auto-tratamento por meio de pessoas que sofrem distúrbios psíquicos ou reação devido um stress social ou econômico uma frustração, ou ainda doença depressiva, ansiedade e fadiga crônica.

4. Meio de não ser aceito socialmente em subcultura.

5. Manifestação de lesão metabólica.

6. Parte de uma rebelião contra valores sociais convencionais relacionados ao prazer.

7. Comportamento apreendido.

8. Resultado de pressões socio-culturais.

O dependente de drogas não consegue desenvolver, realizar suas responsabilidades sociais, o que com freqüência faz com que seja rejeitado. Essa rejeição é agravada pelas mudanças no modo de vida no caráter que passa a apresentar.

Muitas vezes o que pode levar uma pessoa ao uso de drogas são também os fatores ambientais. Quando o indivíduo recebe uma quantidade de estímulos provenientes do meio ambiente em que vive, acima de sua capacidade de absorção de respostas, de integralização, ele entra em stress, sua homeostasia é quebrada. Da mesma forma ambientes sem estímulos podem levá-lo ao desequilíbrio.

Enfim estímulos ambientais e psicossociais podem levar a desvio do comportamento, pois eles afetam diretamente as características emocionais dos indivíduos. Vários são os aspectos psicológicos e psicopatológicos para os farmacodependentes, dos quail citaremos os mais significativos:

\section{1) Curiosidade:}

Normalmente esta é uma das características básicas do adolescente que, continua e continuará sendo o maior contingente de pessoas que usam drogas. Movidos pelo desconhecido e por buscar situações novas eles acabam esbarrando e/ou usando drogas de forma constante.

\section{2) Busca do Prazer (Imediatismo):}

Vivemos uma cultura do resultado imediato, do prático, do acelerado. Resultante imediato de estruturas frágeis de Ego, associadas ao grande incentivo de nosso tempo para as coisas, fatos e objetivos que se apresentam rapidamente e de saciação imediata.

\section{3) Contestação:}

Em função da fase evolutiva que o jovem se encontra normalmente ele busca estruturas de acessos antagônicos aos sociais, seu elemento de afrontamento familiar e social. 


\section{4) Pressões Grupais (Amigos, Clubes, Bairros):}

$\mathrm{Na}$ fase de adolescência o grupo exerce papel importante e fundamental na opinião dos jovens. A aderência a estrutura grupal de amigos, e a fidelidade aos próprios, passa a ser um elemento de grande peso nos jovens. $\mathrm{O}$ vínculo e a relação estabelecidas entre jovens é de muita fidelidade, o que na maioria da vezes não é entendida pelos pais que se sentem colocados à margem da vida dos filhos.

\section{5) Solidão:}

Buscando sempre complementar a falta existente dentro de si, em suas relações de vida. Muitas vezes o ser humano está próximo das pessoas, mas normalmente longe das relações afetivas. O vinculo sempre é muito pobre e estéril.

\section{6) Sentimento de rejeição:}

A busca da droga serve como cumplicidade das grandes dificuldades encontradas por estes indivíduos desde jovens até adultos. O se sentirem rejeitados ecoa dentro de si como sentimento de abandono.

\section{7) Distúrbios das estruturas de personalidade:}

As estruturas neuróticas e psicóticas fazem o papel complementar das grandes influências que jovem se depara, essas estruturas não resolvidas irão manifestar-se como um dos sintomas na busca das drogas.

\section{8) Não suportar frustrações:}

Existe um linear entre conformar-se passivamente com as perdas e rebelar-se agressivamente contra as derrotas. Para alivíar as frustrações o jovem pode lançar mão da negação de sentimentos e buscar o fortalecimento de suas estruturas de onipotência.

\section{9) Não credibilidade de seu potencial:}

Sentimentos de desvalia e um sentimento de auto- valorização baixo, normalmente em função de vários insucessos de sua vida.

\section{0) Insatisfação constante:}

Pouco satisfeito com que faz, sempre buscando saídas mágicas e mirabolantes.

\section{1) Gosto pela novidade, perigo:}

Sempre incorpora a busca da novidade e perigo muito rapidamente, sendo essas características então integradas facilmente em um circo vicioso onde o mecanismo de perda e ganho passa a acontecer com enorme velocidade. 


\section{2) Auto destruição:}

Ao usar qualquer coisa contra si, o autodestrutivo consegue minar suas próprias energias. Tem que acabar com algo dentro e fora de si pois acreditam que tudo de ruim está consigo próprio ou ao seu redor e o bom fora de si.

\section{3) Necessidade de ser aceito pelo grupo:}

O ser igual é ter o mesmo poder de "maturidade" como na fase pubertaria/adolescente o agrupamento normalmente se dá pelos mesmo objetivos de vida, então ser igual é ter o mesmo poder.

\section{4) Insegurança social:}

Sempre ligada com a capacidade de ser aceito pelo grupo de amigos. uma coleção de insucessos, uma punição exagerada ou não) junta, angustia vivida no dia-a-dia sem poder resolvê-las, as dificuldades afetivas relacionais fazem do jovem um grande alvo para o uso de drogas.

\section{5) Síndrome amotivacional:}

Quando as forças vitais estão diminuídas. A capacidade de reação está fragilizada com forte embotamento afetivo. Torna-se distante, pouco afetivo consigo próprio e com seus familiares e amigos. A passividade e o baixo limiar de frustração são características que reforçam sua conduta. Seu grande perigo é desencadear quadros psicóticos.

Estas características são as mais importante nos quadros ocasional, abusivo ou crônico no uso das drogas. A necessidade de experimentar uma droga natural ou sintética é um indício negativo. A procura da necessidade de alterar-se psicologicamente nos revelam características de um ego frágil pouco saudável e pouco resistente em situações do dia-a-dia.

Segundo Rosenfeld, a droga em última instância, "é um meio no qual o toxicômano para aniquilar todo e qualquer objeto e "situação frustradoras e persecutórias".

Por fim ao nosso ver o ponto central da dependência é a relação do crescimento do jovem com as características próprias da adolescência e a sua entrada na fase adulta.

Nos dias atuais a facilidade e a oferta contribui muito para a droga dependência e é em função desta ameaça social que nós profissionais da saúde deveremos estar atento no sentido de ajudar o jovem e sua família com a orientação adequada. 


\section{REFERÊNCIAS BIBLIOGRÁFICAS}

1. DELPIROU, A.; LABROUSE A. Coca-Coke São Paulo. Ed. Erasiliense, 1990.

2. Estratégica nacional para controle das drogas, serviço de divulgação e re lações culturais dos Estados Unidos da América (USIS), 1990.

3. FIORINI, H. Estruturas e abordagem em psicoterápias. RJ, Ed. Francisco Alves, 1989.

4. GRUNSPUN, H. Abuso de drogas psicoativas na adolescência. In MARCONDES E. M.: Pediatria Básica, SP, Sarvier, 1978.

5. OLIEVENSTEIN, C. A droga. SP, Brasiliense, 1992.

6. MATHIS, R. Psicoterapia com adolescentes drogados. Trabalho para Título de Especialista em Psicodrama pela FEBRAP, apresentado n ${ }^{\circ}$ I, Sedes Sapientiae, 1992.

7. MATHIS, R. $34 \%$ dos alunos de escola paga provaram droga. Entrevista a Folha de S. Paulo em 19.02.90.

8. MATHIS. R. Adolescência e legislação, no I Encontro Nacional sobre Políticas de Prevenção na Área da Educação. Secretaria Estadual de Educação de São Paulo, março de 1994. 